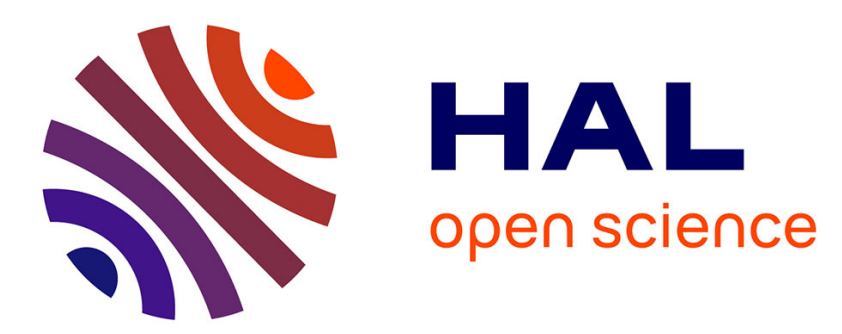

\title{
Extension of the experimental electron density analysis to metastable states: a case example of the spin crossover complex Fe(btr)2(NCS)2.H2O
}

Vincent Legrand, Sébastien Pillet, Mohamed Souhassou, Noël Lugan, Claude Lecomte

\section{To cite this version:}

Vincent Legrand, Sébastien Pillet, Mohamed Souhassou, Noël Lugan, Claude Lecomte. Extension of the experimental electron density analysis to metastable states: a case example of the spin crossover complex Fe(btr)2(NCS)2.H2O. Journal of the American Chemical Society, 2006, 128 (42), pp.1392113931. 10.1021/ja064355f . hal-01006886

\section{HAL Id: hal-01006886 \\ https://hal.science/hal-01006886}

Submitted on 22 Nov 2018

HAL is a multi-disciplinary open access archive for the deposit and dissemination of scientific research documents, whether they are published or not. The documents may come from teaching and research institutions in France or abroad, or from public or private research centers.
L'archive ouverte pluridisciplinaire HAL, est destinée au dépôt et à la diffusion de documents scientifiques de niveau recherche, publiés ou non, émanant des établissements d'enseignement et de recherche français ou étrangers, des laboratoires publics ou privés. 


\title{
Extension of the Experimental Electron Density Analysis to Metastable States: A Case Example of the Spin Crossover Complex $\mathrm{Fe}(\mathrm{btr})_{2}(\mathrm{NCS})_{2} \cdot \mathrm{H}_{2} \mathrm{O}$
}

\author{
Vincent Legrand, ${ }^{\dagger}$ Sébastien Pillet, Mohamed Souhassou, Noël Lugan, ${ }^{\ddagger}$ and \\ Claude Lecomte* \\ Contribution from the Laboratoire de Cristallographie et Modélisation des Matériaux Minéraux \\ et Biologiques, LCM3B, UMR CNRS 7036, Université Henri Poincaré, Nancy I, Faculté des \\ Sciences, BP 239, 54506 Vandoeuvre-les-Nancy, France
}

\begin{abstract}
An experimental electron density (ED) analysis of the spin crossover coordination complex Fe$(\text { btr })_{2}(\mathrm{NCS})_{2} \cdot \mathrm{H}_{2} \mathrm{O}$ has been performed in the ground low-spin (LS) state and in the metastable thermally quenched high-spin (HS) state at $15 \mathrm{~K}$ by fitting a multipolar model to high-resolution X-ray diffraction measurements. The ED has been quantitatively analyzed using the quantum theory of atoms in molecules. This is the first time the ED distribution of a molecular metastable state has been experimentally investigated. The electron deformation densities and derived Fe $3 d$ orbital populations are characteristic of LS $\left(t_{2 g}{ }^{6} e_{g}{ }^{0}\right)$ and $\mathrm{HS}\left(\mathrm{t}_{2 g}{ }^{4} \mathrm{e}_{g}{ }^{2}\right)$ electron configurations and indicate significant $\sigma$ donation to the $\mathrm{Fe} \mathrm{d}_{x^{2}-y^{2}}$ and $\mathrm{d}_{z}{ }^{2}$ atomic orbitals. The $\mathrm{Fe}-\mathrm{N}_{\mathrm{NCS}}$ and $\mathrm{Fe}-\mathrm{N}_{\mathrm{btr}}$ coordination interactions are characterized using the laplacian distribution of the ED, the molecular electrostatic potential, and the fragment charges obtained by integration over the topological atomic basins. A combination of electrostatic and covalent contributions to these interactions is pointed out. Interlayer interactions are evidenced by the presence of bond critical points in $\mathrm{N} \cdots \mathrm{H}$ hydrogen bonds involving the non-coordinated water molecule. Systematic differences in the atomic displacement parameters between the LS and HS states have been described and rationalized in terms of modifications of bond force constants.
\end{abstract}

\section{Introduction}

Experimental electron density (ED) analysis is becoming a very mature field of research with applications in many areas of solid-state physics and chemistry. ${ }^{1}$ This approach has allowed to gain new insights into bonding interactions in solids often from combined experimental and theoretical approaches. Quantitative correlations between the ED features and physical and chemical properties have been derived through the quantum theory of atoms in molecules (QTAIM). ${ }^{2}$ The charge density distribution of molecular electronically excited states has been theoretically investigated by calculations using appropriate configuration interaction methods, like in butadiene or copper complexes for instance. ${ }^{3,4}$ However, on the experimental side, the ED approach has been restricted to systems in the ground state. In recent years, improvements in laboratory and synchrotron diffraction instruments, and mainly the appearance of charge-coupled device (CCD) area detectors, have rendered $\mathrm{X}$-ray diffraction experiments under perturbation technically

$\dagger$ Present address: Institut Laue Langevin, 6 rue Jules Horowitz, BP 156, 38042 Grenoble cedex, France.

$\doteqdot$ On leave from: Laboratoire de Chimie de Coordination du CNRS, 205 Route de Narbonne, 31077 Toulouse Cedex 4, France.

(1) Coppens, P. X-ray Charge Densities and Chemical Bonding; IUCr/Oxford University Press: Oxford, UK, 1997.

(2) Bader, R. F. W. Atoms in molecules: a quantum theory; International Series of Monographs in Chemistry 22; Clarendon Press: Oxford,1990.

(3) Wiberg, K. B.; Hadad, C. M.; Ellison, G. B.; Foresman, J. B. J. Phys. Chem. 1993, 97, 13586.

(4) Coppens, P.; Novozhilova, I. V. Int. J. Quantum Chem. 2005, 101, 611. possible. The number and quality of crystal structures under perturbation are continuously increasing. Among others, hydrostatic pressure, ${ }^{5}$ electric field, ${ }^{6}$ and light irradiation ${ }^{7}$ have been used as external stimuli in conjunction with single-crystal X-ray diffraction techniques for structural analysis purposes. Light-induced phenomena have been much more explored and even extended to time-resolved experiments, so that several instruments have been specially designed and devoted to lightinduced diffraction experiments. ${ }^{8-11}$ In addition, new leastsquares refinement procedures have been implemented for the specific fitting of the structural reorganizations consecutive to a perturbation. ${ }^{12}$ The reconstruction of the periodic ED distribution of light-induced metastable states from single-crystal diffraction data is a challenging task which requires several essential conditions. ${ }^{13}$ The data collections have to be performed on well-crystallized samples at low or even very low temper-

(5) Katrusiak, A. Acta Crystallogr. 2004, A60, 409.

(6) Hansen, N. K.; Fertey, P.; Guillot, R. Acta Crystallogr. 2004, A60, 465

(7) Coppens, P.; Vorontsov, I. I.; Graber, T.; Gembicky, M.; Kovalevsky, A. Y. Acta Crystallogr. 2005, A61, 162.

(8) White, M. A.; Pressprich, M. R.; Coppens, P.; Coppens, D. D. J. Appl. Crystallogr. 1994, 27, 727.

(9) Wulff, M.; Schotte, F.; Naylor, G.; Bourgeois, D.; Moffat, K.; Mourou, G. Nucl. Instrum. Methods 1997, A398, 69.

(10) Fullagar, W. K.; Wu, G.; Kim, C.; Ribaud, L.; Sagerman, G.; Coppens, P. J. Synchrotron Radiat. 2000, 7, 229.

(11) Coppens, P. (with contributions from Cox, D. E.; Vlieg, E.; Robinson, I. K.). Synchrotron-Radiation Crystallography; Academic Press: London, 1992; pp 143-146.

(12) Ozawa, Y.; Pressprich, M. R.; Coppens, P. J. Appl. Crystallogr. 1998, 31 , 128.

(13) Cole, J. M. Acta Crystallogr. 2004, A60, 472. 
atures to decrease, as much as possible, thermal smearing effects. The diffraction data should be free from any systematic errors (absorption, extinction, thermal diffuse scattering) and extend to very high resolution in reciprocal space. Stability versus time of the probed system (ground or metastable) is crucial; in other words, if one aims at studying a metastable state, the relaxation to the ground state has to be quenched or at least well controlled. The flexibility and adequacy of the model used to reconstruct the ED are essential; in general, an elaborated multipolar model based on a pseudo-atomic approximation is employed.

Owing to their high electronic and structural contrast and the very long lifetime of the metastable state at sufficiently low temperature, spin transition materials are good candidates for accurate ED analysis of metastable states. Spin transition coordination complexes have received increasing interest thanks to their intrinsic molecular bistability properties. ${ }^{14,15}$ These materials consist of a $\mathrm{d}^{4}$-to- $\mathrm{d}^{7}$ transition metal coordinated to specific, usually nitrogen-containing aromatic ligands whose ligand field is intermediate between weak and strong. Correlatively, the electron configuration of the central metal ion is temperature dependent; a conversion from high-spin (HS) to low-spin (LS) molecular species occurs on decreasing the temperature. In the case of octahedral iron(II) complexes, the transition involves the formal $\mathrm{t}_{2 \mathrm{~g}}{ }^{6} \mathrm{e}_{\mathrm{g}}{ }^{0}$ (LS) and $\mathrm{t}_{2 \mathrm{~g}}{ }^{4} \mathrm{e}_{\mathrm{g}}{ }^{2}$ (HS) electron configurations. The spin transition is associated with drastic changes of the molecular structure: a shortening of the $\mathrm{Fe}-\mathrm{N}$ bond distances by $\sim 0.2 \AA$ and a less distorted octahedral geometry are typically observed upon the HS-to-LS conversion. ${ }^{16}$ It has been shown that small substitution modifications of the ligand can lead to severe perturbation of the spin transition characteristics and can even suppress the transition. One of the reasons could be the associated change of the ligand electronic properties, such as $\sigma$ donor and $\pi$ acceptor capability, disturbing the ligand field at the central metal site, or more generally, any change in interatomic interactions. The HS-to-LS conversion is a purely molecular process whose characteristics in the solid state are tuned by several parameters, like the presence of solvent molecules or counterions in the void of the crystal structure or the strength of intermolecular contacts. In some instances, the spin transition is furthermore associated with a structural phase transition. The spin transition can be triggered using several kinds of external stimuli, like pressure, ${ }^{17}$ intense magnetic field ${ }^{18}$ or light excitation. ${ }^{19}$ The mechanism of the light-induced LS-to-HS transition (light-induced excited spin state trapping (LIESST) phenomenon) has been elucidated by optical spectroscopic investigations, ${ }^{20}$ and the corresponding crystal structures of several light-induced metastable HS states have been derived. ${ }^{21-23}$ It has also been shown that a metastable HS state

(14) Gütlich, P.; Hauser, A.; Spiering, H. Angew. Chem., Int. Ed. Engl. 1994, 33, 2024.

(15) Gutlich P., Goodwin, H. A., Eds. Topics in Current Chemistry; SpringerVerlag: Berlin, 2004; Vols. 233, 234, and 235.

(16) Guionneau, P.; Marchivie, M.; Bravic, G.; Létard, J.-F.; Chasseau, D. Topics in Current Chemistry; Springer-Verlag: Berlin, 2004; Vol. 234, pp 97.

(17) Gütlich, P.; Ksenofontov, V.; Gaspar, A. B. Coord. Chem. Rev. 2005, 249, 1811.

(18) Bousseksou, A.; Varret, F.; Goiran, M.; Boukheddaden, K.; Tuchagues, J.-P. Topics in Current Chemistry; Springer-Verlag: Berlin, 2004, Vol. 235, pp 65.

(19) Decurtins, S.; Gütlich, P.; Köhler, C. P.; Spiering, H. Chem. Phys. Lett. 1984, 105,1 .

(20) Hauser, A. Chem. Phys. Lett. 1992, 192, 65

(21) Marchivie, M.; Guionneau, P.; Howard, J. A. K.; Chastanet, G.; Létard, J. F.; Goeta, A. E.; Chasseau, D. J. Am. Chem. Soc. 2002, 124, 194.

(22) Kusz, J.; Schollmeyer, D.; Spiering, H.; Gütlich, P. J. Appl. Crystallogr. 2005, 38,528 . can be obtained by rapid thermal quenching from room temperature to very low temperature; the corresponding crystal structure has been determined. ${ }^{24}$ It is still controversial whether the metastable HS phases obtained either by light or by thermal quenching and the room-temperature HS phase are structurally identical, although similar structural properties have been evidenced. For highly cooperative spin crossover systems, the relaxation of the metastable HS state is very slow at very low temperature (typically $T<50 \mathrm{~K}$ ), due to a phonon-assisted tunnel mechanism; at higher temperatures $(T>50 \mathrm{~K})$, the HSto-LS relaxation rate is temperature dependent and several orders of magnitude faster. Furthermore, the relaxation rate does not follow single-exponential kinetics, attributed to an auto-accelerated phenomenon due to the HS-to-LS large molecular volume change and long-range elastic interactions in the solid.

$\mathrm{Fe}(\mathrm{btr})_{2}(\mathrm{NCS})_{2} \cdot \mathrm{H}_{2} \mathrm{O}$ is one of the most studied spin crossover complexes owing to its high cooperative behavior (btr is $4,4^{\prime}$ bis-1,2,4-triazole). For this material, the HS-to-LS thermal transition is complete and abrupt with $21 \mathrm{~K}$ hysteresis $\left(T_{1 / 2 \downarrow}=\right.$ $\left.123.5 \mathrm{~K}, T_{1 / 2 \uparrow}=144.5 \mathrm{~K}\right){ }^{25}$ Its crystal structure consists of bidimensionnal extended layers built from $\mathrm{Fe}(\mathrm{II})$ ions in an octahedral surrounding of two NCS groups in trans position and four btr ligands in the basal plane, with bond distances of $d_{\mathrm{Fe}-\mathrm{N}}=2.125(3) \AA, d_{\mathrm{Fe}-\mathrm{N} 11}=2.180(3) \AA$, and $d_{\mathrm{Fe}-\mathrm{N} 21}=$ 2.188(2) $\AA$ in the HS state at room temperature (Figure 1). The two-dimensional layers are connected through van der Waals interactions and hydrogen bonds supported by non-coordinated water molecules. The thermal spin transition and especially the hysteresis loop have been studied using various techniques, like magnetic susceptibility measurements and Mössbauer spectroscopy. ${ }^{25}$ The thermal HS-to-LS transition has been structurally characterized by single-crystal diffraction, ${ }^{26}$ where it has been shown that the transition occurs through a domain nucleation and growth process in the solid state. The effects of metal dilution in the $\mathrm{Fe}_{x} \mathrm{Co}_{1-x}(\text { btr })_{2}(\mathrm{NCS})_{2} \cdot \mathrm{H}_{2} \mathrm{O}$ and $\mathrm{Fe}_{x} \mathrm{Ni}_{1-x}(\text { btr })_{2-}$ $(\mathrm{NCS})_{2} \cdot \mathrm{H}_{2} \mathrm{O}$ isostructural series have been studied by calorimetric, magnetic, and Mössbauer measurements. ${ }^{27,28}$ Iron(II) dilution smoothes the transition curves, related to a decrease in cooperativity. The light-induced properties of $\mathrm{Fe}(\mathrm{btr})_{2}(\mathrm{NCS})_{2}$ • $\mathrm{H}_{2} \mathrm{O}$ have been pointed out by reflectivity and photomagnetic measurements ${ }^{29}$ and indicate that a quantitative photoinduced population of the metastable HS state is hard to attain in the pure $\mathrm{Fe}$ compound but easier in the $\mathrm{Co}$ or Ni diluted ones. A complete conversion has nevertheless been reached in a singlecrystal X-ray diffraction measurement under light excitation of the pure Fe compound using high laser power at $\lambda=488 \mathrm{~nm}^{30}$ In addition, a thermal quenching procedure allowed a metastable HS state to be trapped at $15 \mathrm{~K}$, which has been further magnetically and structurally characterized. The crystal structures of the different spin states (room temperature HS, low

(23) Legrand, V.; Carbonera, C.; Pillet, S.; Souhassou, M.; Létard, J. F.; Guionneau, P.; Lecomte, C. J. Phys. Conf. Ser. 2005, 21, 73.

(24) Marchivie, M.; Guionneau, P.; Létard, J. F.; Chasseau, D.; Howard, J. A. K. J. Phys. Chem. Solids 2004, 65, 17.

(25) Vreugdenhil, W.; Van Diemen, J. H.; De Graaff, R. A. G.; Haasnoot, J. G.; Reedijk, J.; Van Der Kraan, A. M.; Kahn, O.; Zarembowitch, J. Polyhedron 1990, 9, 2971.

(26) Pillet, S.; Hubsch, J.; Lecomte, C. Eur. J. Phys. B 2004, 38, 541.

(27) Martin, J.-P.; Zarembowitch, J.; Bousseksou, A.; Dworkin, A.; Haasnoot, J. G.; Varret, F. Inorg. Chem. 1994, 33, 6325.

(28) Martin, J.-P.; Zarembowitch, J.; Dworkin, A.; Haasnoot, J. G.; Codjovi, E. Inorg. Chem. 1994, 33, 2617.

(29) Desaix, A.; Roubeau, O.; Jeftic, J.; Haasnoot, J. G.; Boukheddaden, K.; Codjovi, E. Eur. Phys. J. 1998, B6, 183.

(30) Legrand V. Ph.D. thesis, University Henri Poincaré, Nancy I, France, 2005 

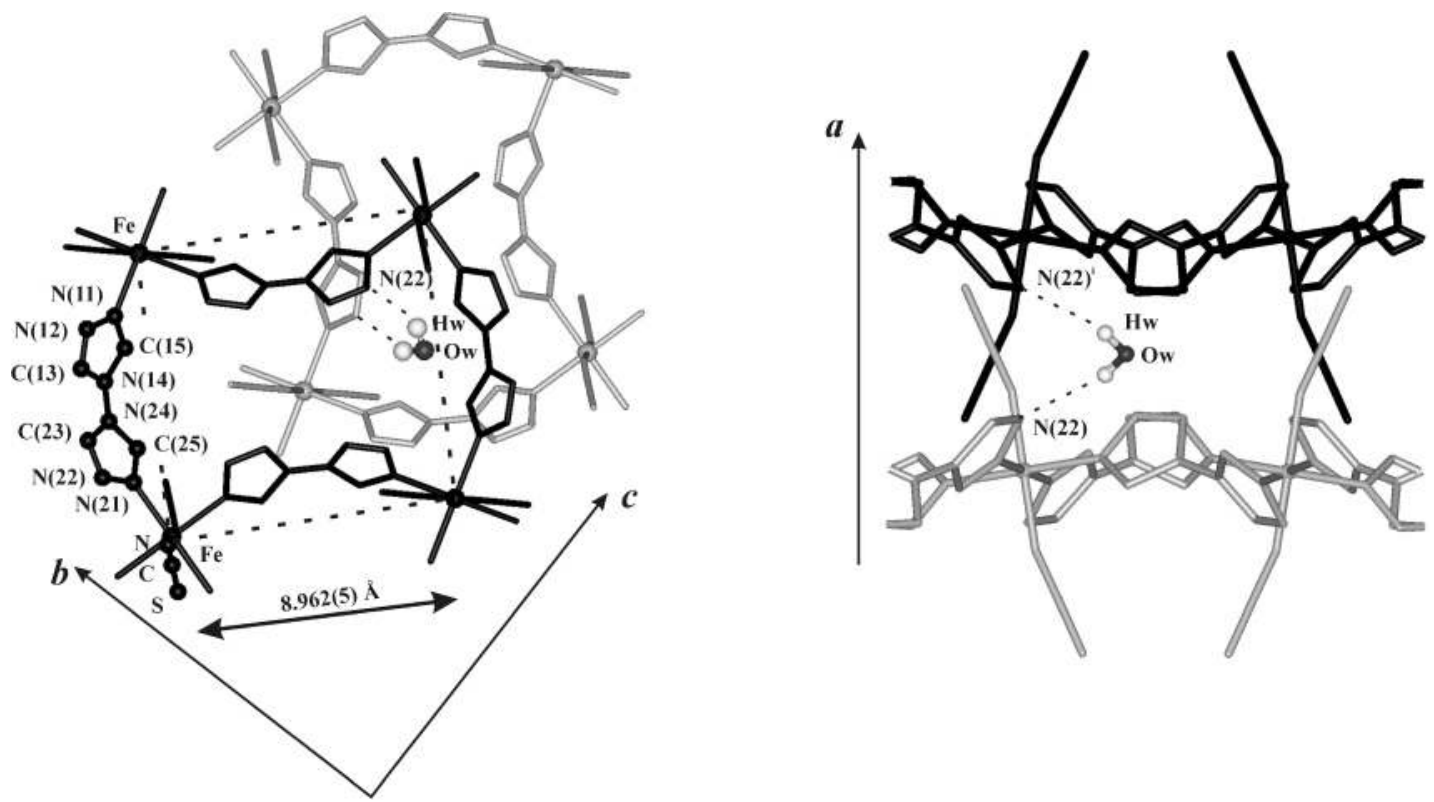

Figure 1. Crystal structure of $\mathrm{Fe}(\mathrm{btr})_{2}(\mathrm{NCS})_{2} \cdot \mathrm{H}_{2} \mathrm{O}$ in the LS state at $104 \mathrm{~K} . \mathrm{H}$ atoms from the btr groups have been omitted for clarity.

temperature LS, light-induced metastable HS, and thermally quenched metastable HS) have been comparatively analyzed in detail. ${ }^{30}$ We report here a detailed and comparative analysis of the ED distribution of $\mathrm{Fe}(\mathrm{btr})_{2}(\mathrm{NCS})_{2} \cdot \mathrm{H}_{2} \mathrm{O}$ in the $\mathrm{LS}$ and metastable HS states.

\section{Experimental Section}

The bis-triazole ligand and the $\mathrm{Fe}(\mathrm{btr})_{2}(\mathrm{NCS})_{2} \cdot \mathrm{H}_{2} \mathrm{O}$ complex were synthesized as reported earlier. ${ }^{31}$ Well-shaped samples were embodied in vacuum grease to prevent crystal degradation on passing through the spin transition and mounted on glass fiber. X-ray diffraction measurements were performed using an Oxford diffractometer equipped with a CCD area detector and graphite-monochromatized Mo $\mathrm{K \alpha}$ radiation. Very low temperatures were obtained using a Helijet openflow He cryosystem. The temperature at the sample position was beforehand calibrated using the tetragonal-to-orthorhombic structural phase transition of $\mathrm{DyVO}_{4}$ at $T=14 \mathrm{~K}$. The temperature instability was checked throughout the measurement and did not exceed $0.2 \mathrm{~K}$. Owing to the small size of the samples, a temperature gradient is negligible, the He flux being homogeneous and linear at the sample position. The diffraction measurement conditions had to be perfectly optimized since the liquid $\mathrm{He}$ container limits the experiment duration to at most $40 \mathrm{~h}$, and therefore limits the accuracy.

Low-Spin Ground-State Data Collection and Reduction. Diffraction measurements in the LS state were performed at $T=15 \mathrm{~K}$ by $\omega$-scans using a detector-to-sample distance of $60 \mathrm{~mm}$ and several detector $2 \theta$ positions to ensure a high resolution and coverage of reciprocal space. The diffraction peaks on collected frames were integrated with the CRYSALIS software, ${ }^{32}$ and a frame-to-frame scaling procedure was used to correct for slight crystal decay. Final cell parameters were derived using a least-squares post-refinement on all measured reflections. The crystal faces were indexed, and an analytical absorption correction was applied, leading to minimum and maximum transmission coefficients of 0.68 and 0.83 , respectively. A total of 26316 reflections were collected and merged into 6407 symmetryunique reflections in the $2 / m$ Laue group (space group $C 2 / c$ ) using SORTAV. ${ }^{33}$ The high resolution of the experiment $\left(S=0.98 \AA^{-1}\right)$ and the low internal agreement factor $\left(R_{\mathrm{int}}=0.034\right.$ for all data) show the

(31) Haasnoot, J. G.; Groeneveld, W. L. Z. Naturforsch. 1979, 34b, 1500.

(32) Oxford Diffraction. CrysAlis CCD and CrysAlis RED, Versions 1.171; Oxford Diffraction: Wroclaw, Poland, 2004.
Table 1. Crystallographic Data and Experimental Details

\begin{tabular}{|c|c|c|}
\hline & LS & HS \\
\hline space group & $C 2 / c$ & $C 2 / c$ \\
\hline$a(\AA)$ & $11.1626(4)$ & $10.9047(5)$ \\
\hline$b(\AA)$ & $12.5839(6)$ & $13.1125(6)$ \\
\hline$c(\AA)$ & $12.7543(6)$ & $13.162(1)$ \\
\hline$\beta\left({ }^{\circ}\right)$ & $92.284(3)$ & $90.883(8)$ \\
\hline$V\left(\AA^{3}\right)$ & $1790.2(1)$ & $1881.7(2)$ \\
\hline$Z$ & 4 & 4 \\
\hline radiation type & $\begin{array}{l}\text { Mo K } \alpha \\
(\lambda=0.71073 \AA)\end{array}$ & $\begin{array}{l}\text { Mo K } \alpha \\
(\lambda=0.71073 \AA)\end{array}$ \\
\hline crystal size (mm) & $0.32 \times 0.20 \times 0.013$ & $0.36 \times 0.18 \times 0.12$ \\
\hline$\mu\left(\mathrm{mm}^{-1}\right)$ & 1.10 & 1.05 \\
\hline$T_{\min } / T_{\max }$ & $0.68 / 0.83$ & $0.80 / 0.89$ \\
\hline$T(\mathrm{~K})$ & 15 & 15 \\
\hline $\begin{array}{l}\text { measured reflections } \\
\text { unique reflections } \\
\text { redundancy } \\
R_{\text {int }}(I) \\
\sin \theta / \lambda_{\max }\left(\AA^{-1}\right)\end{array}$ & $\begin{array}{l}\text { Data Reduction } \\
26316 \\
6407 \\
4.1 \\
0.034 \\
0.98\end{array}$ & $\begin{array}{l}16975 \\
3879 \\
4.4 \\
0.033 \\
0.85\end{array}$ \\
\hline & IAM Refinement & \\
\hline$N_{\text {par }}$ & 149 & 149 \\
\hline$R$ (all data) & 0.039 & 0.035 \\
\hline$R_{\mathrm{W}}$ (all data) & 0.028 & 0.020 \\
\hline \multirow[t]{2}{*}{$\begin{array}{l}\text { goodness of fit } \\
\text { (all data) }\end{array}$} & 2.37 & 1.55 \\
\hline & ultipolar Refinement & \\
\hline$N_{\text {par }}$ & 245 & 245 \\
\hline$R\left(S<0.7 \AA^{-1} /\right.$ all data $)$ & $0.018 / 0.032$ & $0.022 / 0.032$ \\
\hline$R_{\mathrm{W}}\left(S<0.7 \AA^{-1} /\right.$ all data $)$ & $0.015 / 0.017$ & $0.014 / 0.015$ \\
\hline $\begin{array}{l}\text { goodness of fit } \\
\qquad\left(S<0.7 \AA^{-1} / \text { all data }\right)\end{array}$ & $1.78 / 1.44$ & $1.34 / 1.17$ \\
\hline
\end{tabular}

high quality and internal consistency of the measured data. Owing to the limited available experiment duration, the mean redundancy is only 4.1. All details about data collection and reduction are summarized in Table 1.

High-Spin Metastable-State Data Collection and Reduction. For the high-spin state, diffraction data collection had to be performed under controlled specific conditions to ensure, at the same time, a complete population of the metastable state and a HS-to-LS quenched relaxation.

(33) Blessing, R. H. J. Appl. Crystallogr. 1989, 22, 396. 


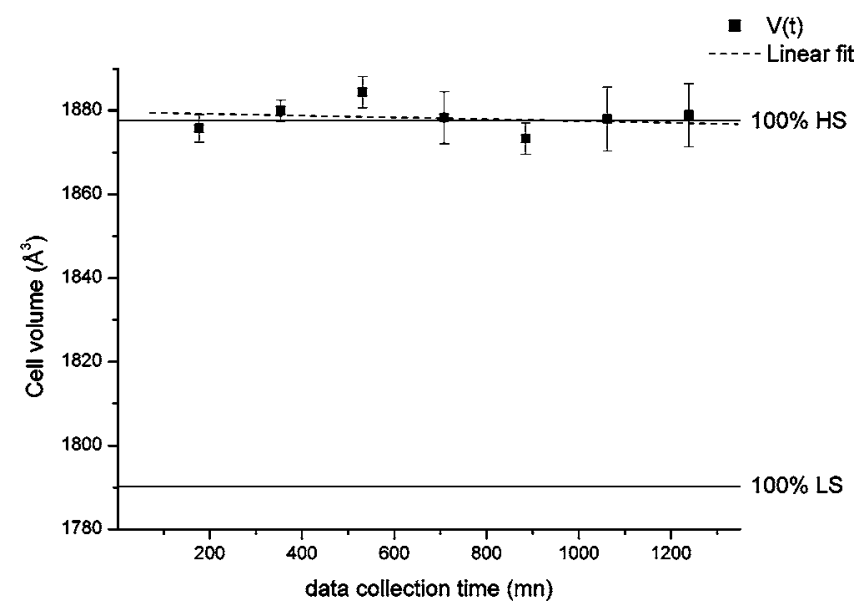

Figure 2. Evolution of the unit cell volume versus time during the X-ray data collection and linear least-squares fit $(V(t)=1880(3)-0.002(5) t)$. The differences in standard deviation are due to different reciprocal space coverage versus time.

In such a cooperative system, the quenched state is obtained by a drastic slowing of the HS-to-LS relaxation process at very low temperature, which prevents thermal equilibrium to the thermodynamically stable LS state. According to our prior magnetic measurements, an almost complete HS metastable state can be trapped at $15 \mathrm{~K}$ using a rapid temperature decrease from room temperature. ${ }^{23}$ In the present X-ray diffraction experiment, the following procedure has been applied. Prior to the low-temperature measurement, a single crystal of $\mathrm{Fe}(\mathrm{btr})_{2}(\mathrm{NCS})_{2}$. $\mathrm{H}_{2} \mathrm{O}$ was carefully centered on a goniometer head on the diffractometer at room temperature. The goniometer head supporting the sample was removed from the diffractometer in order to decrease the temperature to $T=15 \mathrm{~K}$. The crystal (already centered) was then thermally quenched by remounting it directly and as quickly as possible on the diffractometer under the He cooling gas stream. Under such conditions, thermal equilibrium is reached in less than $1 \mathrm{~s}$, which ensures that the sample is perfectly quenched in the metastable state. Compared to our prior magnetic measurements under similar conditions, the present quenching procedure is far quicker; the transition completeness is confirmed by the bond distances and angles of the corresponding crystal structure (vide infra). No space group change or structural phase transition was evident after thermal quenching. Full data collection and reduction were performed using the same procedure as for the LS ground state. By comparison, the resolution of the metastable state experiment is slightly lower $\left(S=0.85 \AA^{-1}\right)$, but the internal consistency $\left(R_{\text {int }}=0.033\right)$ is in the same range for a similar data redundancy. Correlatively, the number of symmetry-independent reflections is lower than for the LS ground state. The limited resolution of the HS data collection can be understood from the genuine metastable nature of the probed system. Indeed, the scattering resolution (in $\sin (\theta) / \lambda$ ) of a diffraction experiment is intimately related to the quality of long-range order in the sample, which could be slightly worse for such a metastable state. At $15 \mathrm{~K}$, the HS-to-LS relaxation of $\mathrm{Fe}(\mathrm{btr})_{2}(\mathrm{NCS})_{2} \cdot \mathrm{H}_{2} \mathrm{O}$ is very slow, as quantified by prior magnetic measurements. The evolution of the cell volume along the data collection can be used for estimating the relaxation rate, ${ }^{34}$ since the HS and LS cell volumes differ by more than $90 \AA^{3}$ at the same measurement temperature $\left(V_{\mathrm{HS}}=1881.7(2)\right.$ $\left.\AA^{3}, V_{\mathrm{LS}}=1790.2(1) \AA^{3}\right)$. The evolution of the cell volume during the experiment (Figure 2) exhibits a slight linear trend with a negative but

(34) Since the unit cell volume largely differs between pure HS $\left(\gamma_{\mathrm{HS}}=1.0\right)$ and LS $\left(\gamma_{\mathrm{HS}}=0.0\right)$ states for spin crossover materials, the unit cell volume and $\operatorname{LS}\left(\gamma_{\mathrm{HS}}=0.0\right)$ states for spin crossover materials, the unit cell volume
is a function of the fraction of HS species $\gamma_{\mathrm{HS}}$ for intermediate composition $\left(0.0<\gamma_{\mathrm{HS}}<1.0\right)$. Assuming a linear dependence of the cell volume with $\gamma_{\mathrm{HS}}$, it can be approximated by $V(t)=\gamma_{\mathrm{HS}}(t) V_{\mathrm{HS}}+\left(1-\gamma_{\mathrm{HS}}(t)\right) V_{\mathrm{LS}}$, where $V(t)$ is the volume refined at time $t, V_{\mathrm{HS}}$ and $V_{\mathrm{LS}}$ correspond to the volume of purely HS and LS states, respectively, at the measurement temperature. Knowing $V_{\mathrm{HS}}$ and $V_{\mathrm{LS}}$ and measuring $V(t)$, the $\gamma_{\mathrm{HS}}(\mathrm{t})$ curve can easily be derived from the previous equation. nonsignificant slope $(V(t)=1880(3)-0.002(5) t)$, which can rule out real relaxation during our diffraction measurement; at least, relaxation need not be taken into account in the least-squares process.

Electron Density Refinements of the Low-Spin Ground State. The structure of $\mathrm{Fe}(\mathrm{btr})_{2}(\mathrm{NCS})_{2} \cdot \mathrm{H}_{2} \mathrm{O}$ in the LS state at $15 \mathrm{~K}$ has been refined by least-squares using SHELXL ${ }^{35}$ and reported elsewhere. ${ }^{30}$ The corresponding atomic positions and displacement parameters were used as starting parameters for the ED refinement using the program MOLLY. ${ }^{36}$ This latter implements the Hansen-Coppens pseudo-atomic multipolar expansion of the ED: ${ }^{37}$

$$
\rho(\vec{r})=\rho_{\text {core }}(r)+P_{\text {val }} \kappa^{3} \rho_{\text {val }}(\kappa r)+\sum_{l} \kappa^{\prime 3} R_{l}\left(\kappa^{\prime} r\right) \sum_{m=0}^{l} P_{l m \pm} y_{l m \pm}(\theta, \varphi)
$$

where $\rho_{\text {core }}(r)$ and $\rho_{\text {val }}(r)$ are spherically averaged core and valence EDs calculated from Clementi Hartree-Fock wave functions for groundstate isolated atoms. ${ }^{38} \kappa$ and $\kappa^{\prime}$ are contraction-expansion parameters, and $P_{\text {val }}$ is the atomic valence shell electron population. The deformation of the valence electron shell is projected on real spherical harmonics $y_{l m} \pm(\theta, \varphi)$ times Slater-type radial functions $R_{n l}(r)=N_{l} r_{l}^{n_{l}} \exp \left(-\xi_{l} r\right)$. Initial coefficients $n_{l}$ and $\xi_{l}$ were taken from the energy-optimized Slater-type exponents of Clementi and Raimondi. ${ }^{39}$

In the first step, for a better deconvolution of thermal smearing effects, a multipolar transfer procedure was exploited. Prior multipolar EDs of the NCS and btr groups have been determined by high-resolution diffraction experiments on single crystals of KNCS and btr. ${ }^{30}$ The corresponding atomic ED parameters $\left(P_{\text {val }}, \kappa, \kappa^{\prime}, P_{l m}\right)$ were transferred to the NCS and btr groups in $\mathrm{Fe}(\mathrm{btr})_{2}(\mathrm{NCS})_{2} \cdot \mathrm{H}_{2} \mathrm{O}$ with identical radial basis functions.

The scale factor, atomic positions, and anisotropic (isotropic for hydrogen atoms) displacement parameters were then refined on all data. The $\mathrm{C}-\mathrm{H}$ and $\mathrm{O}-\mathrm{H}$ distances were adjusted to the usual neutron values of 1.08 and $0.95 \AA$, respectively. ${ }^{40}$ At this stage of the refinement, the Hirshfeld rigid bond test ${ }^{41}$ is fulfilled for all interatomic bonds except the $\mathrm{Fe}-\mathrm{N}$ ones. This indicates that a correct deconvolution of thermal smearing effects has been achieved by the multipolar transfer and subsequent refinement of displacement parameters. ${ }^{42}$ The initial [Ar]$3 \mathrm{~d}^{6} 4 \mathrm{~s}^{2}$ electron configuration was assumed for iron; the $3 \mathrm{~d}$ and $4 \mathrm{~s}$ electron contributions were first accounted for using two monopoles $\left(P_{\text {val }}\right.$ and $\left.P_{00}\right)$. Preliminary tests of the refinement were unsuccessful in the fitting of the $P_{00}$ term, owing to the diffuseness of the $4 \mathrm{~s}$ electrons in direct space. Therefore, the $P_{00}$ population was fixed and constrained to two electrons; $P_{00}=0$ and $P_{00}=1$ lead to worse refinement agreement factors and higher residual EDs. Several noncrystallographic molecular symmetries were imposed during the refinement: the NCS group was restricted to cylindrical symmetry, whereas the two triazole rings were constrained to chemical equivalence. In addition, for triazole, a single $\left(\kappa, \kappa^{\prime}\right)$ set was assumed and refined for each atom type $(\mathrm{C}, \mathrm{N}$, $\mathrm{H})$. The multipolar expansion was truncated at the hexadecapolar level for $\mathrm{Fe}$, the octupolar level for $\mathrm{N}, \mathrm{C}, \mathrm{O}$, and $\mathrm{S}$, and the dipolar level for $\mathrm{H}$ atoms. For $\mathrm{Fe}$, only the quadrupolar and hexadecapolar terms were refined, in accordance with the site symmetry (inversion center). The Fe local coordinate system was defined according to the coordination sphere, with $z$ in the NCS direction and $x$ and $y$ in the basal plane toward N11 and N21, respectively.

The agreement factors at the end of the multipolar refinement were $R=0.032$ and $R_{\mathrm{w}}=0.017$ on all data, indicating a good agreement

(35) Sheldrick, G. M. SHELX97, Program for structure solution and refinement: University of Gottingen, Germany, 1997.

(36) Hansen, N. K.; Coppens, P. Acta Crystallogr. 1978, A34, 909.

(37) Stewart, R. F. Chem. Phys. Lett. 1979, 65, 335.

(38) Clementi, E.; Roetti, C. At. Data Nucl. Data Tables 1974, 14, 177.

(39) Clementi, E.; Raimondi, D. L. J. Chem. Phys. 1963, 38, 2686.

(40) Allen, F. H. Acta Crystallogr. 1986, B42, 515.

(41) Hirshfeld, F. L. Acta Crystallogr. 1976, A32, 239

(42) Pichon-Pesme, V.; Lecomte, C.; Lachekar, H. J. Phys. Chem. 1995, 99, 6242 . 


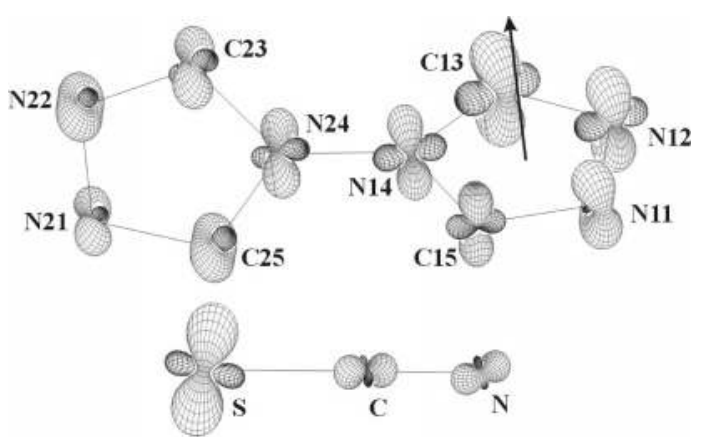

Figure 3. PEANUT plot ${ }^{43}$ showing the RMS surfaces of the difference between the HS and LS atomic displacement parameters at the $100 \%$ probability level. Positive surface is shown in gray, negative in black. The arrow shows the direction perpendicular to the triazole ring on the righthand side.

between the ED model and the X-ray diffraction data. The residual ED (difference between the observed and modeled multipolar ED given in eq 1) is given in the Supporting Information and does not show any significant features, except for some residues around $\mathrm{Fe}$ (maximum 0.3 e $\AA^{-3}$ ).

Electron Density Refinements of the High-Spin Metastable State. The refinement strategy used for the HS metastable state was identical to the LS one, with the same multipolar transfer of the NCS and btr EDs to better deconvolute thermal smearing effects. The crystal structure indicates a slight static disorder of the $\mathrm{S}$ atom, which was refined as two independent positions. Such a disorder is not uncommon in NCScontaining spin transition complexes. The two $\mathrm{S}$ positions were introduced in the multipolar refinement and the complementary occupancies refined to 0.0300(5) and 0.9700(5) for the minor and major positions, respectively. As for the HS state, the Hirshfeld rigid bond test is fulfilled for all interatomic bonds except for $\mathrm{Fe}-\mathrm{N}$ ones, which shows that a correct deconvolution of thermal smearing effects has been achieved and that the static disorder of $\mathrm{S}$ is limited. One might expect that this latter does not perturb too much the multipolar fitting of the ED. In the refinement of the electron deformation density, evidently, no electron deformation density refinement was made on the $\mathrm{S}$ atom in the minor position. Similar chemical and symmetry constraints have been applied as in the LS state. The agreement factors at the end of the multipolar refinement are similar to those of the LS state, $R=$ 0.032 and $R_{\mathrm{w}}=0.015$ on all data; the residual ED is reported in the Supporting Information.

\section{Results and Discussion}

Thermal Motion Analysis. It is well known that the atomic displacement parameters derived from X-ray diffraction measurements are biased by the electron deformation density. However, the use of a multipolar expansion of the ED ensures a better deconvolution of thermal smearing effects from the deformation density than a purely structural model. The anisotropic displacement parameters obtained from our multipolar fitting are then good estimates of the atomic thermal vibrations. As the two diffraction measurements (LS and HS) have been performed at the same temperature, the differences in atomic displacement tensors $\left(\mathbf{U}_{i j}\right)$ represent the modification of vibration modes and amplitudes upon the spin transition.

As shown by the root-mean-square (RMS) surfaces of the difference between the HS and LS atomic displacement parameters (Figure 3), ${ }^{43}$ the amplitudes of thermal motion are systematically higher in the HS state than in the LS one. The difference exhibits a systematic trend, the thermal motion being

(43) Hummel, W.; Hauser, J.; Büergi, H.-B. J. Mol. Graph. 1990, 8, 214-220.
Table 2. Mean Square Displacement Amplitude (MSDA in $\AA^{2}$ ) along Selected Bond Axis

\begin{tabular}{llcc}
\hline bond & & LS state & HS state \\
\hline $\mathrm{Fe}-\mathrm{N}$ & $\mathrm{Fe}$ & $0.0042(1)$ & $0.0046(1)$ \\
& $\mathrm{N}$ & $0.0061(1)$ & $0.0074(1)$ \\
$\mathrm{Fe}-\mathrm{N} 11$ & $\mathrm{Fe}$ & $0.0037(1)$ & $0.0041(1)$ \\
& $\mathrm{N} 11$ & $0.0047(1)$ & $0.0089(1)$ \\
$\mathrm{Fe}-\mathrm{N} 21$ & $\mathrm{Fe}$ & $0.0042(1)$ & $0.0039(1)$ \\
& $\mathrm{N} 21$ & $0.0060(1)$ & $0.0054(1)$ \\
$\mathrm{N}-\mathrm{C}$ & $\mathrm{N}$ & $0.0060(1)$ & $0.0082(1)$ \\
& $\mathrm{C}$ & $0.0068(1)$ & $0.0073(1)$ \\
$\mathrm{C}-\mathrm{S}$ & $\mathrm{C}$ & $0.0068(1)$ & $0.0073(1)$ \\
& $\mathrm{S}$ & $0.0059(1)$ & $0.0091(1)$ \\
\hline
\end{tabular}

higher in the direction perpendicular to each triazole ring. In the case of $\mathrm{S}$, the thermal motion is higher in the direction perpendicular to the NCS axis in the HS state. As mentioned in the Experimental Section, $\mathrm{S}$ presents some disorder in the HS state; this disorder has been treated using a split atomic position over two main positions. This could be oversimplified, and a continuous distribution of $\mathrm{S}$ atom positions could be a more realistic model, but this is hard to describe using a pseudoatomic model of the ED. In fact, static disorder cannot be separated from purely thermal contributions from a diffraction experiment performed at a single temperature. It is to be noted that an identical and enhanced HS-LS difference has been evidenced at $130 \mathrm{~K}$ in the thermal hysteresis loop and will be described in more detail elsewhere. Compared to the $130 \mathrm{~K}$ case, the HS-LS difference in atomic displacement parameters is reduced at $15 \mathrm{~K}$; the effect is therefore temperature dependent. The influence of static disorder on $\mathrm{S}$ is thus less probable than a real difference in vibrational amplitudes. At our measurement temperature $(15 \mathrm{~K})$, the thermal displacement parameters are supposed to be almost temperature independent and should reflect only the zero-point vibrations.

The thermal motion of the btr group has been further analyzed using the TLS formalism, considering btr as a rigid molecular entity. The translation $\mathbf{T}$ and libration $\mathbf{L}$ matrix elements have been fitted in both spin states with respect to the molecular inertial axis against the atomic displacement parameters from our ED model. ${ }^{44,45}$ This rigid-body motion describes quite well the thermal motion of all the btr atoms $\left(R_{\mathrm{w}}(\mathrm{HS})=0.10, R_{\mathrm{w}^{-}}\right.$ $(\mathrm{LS})=0.09$ ). The residual $\Delta U=U_{\text {mult }}-U_{\mathrm{TLS}}$ (given in the Supporting Information) does not exhibit any systematic features which would require the introduction of additional degrees of freedom corresponding to internal vibrational modes. The obtained external translation amplitudes are systematically higher in the HS state $\left(T 1=0.0083(4) \AA^{2}, T 2=0.0076(4) \AA^{2}\right.$, $T 3=0.0058(2) \AA^{2}$ with respect to the inertial axis system) than in the LS state $\left(T 1=0.0071(4) \AA^{2}, T 2=0.0070(4) \AA^{2}, T 3=\right.$ $\left.0.0051(2) \AA^{2}\right)$. On the other hand, the libration amplitude along the $z$ molecular axis $(\mathrm{N} 14-\mathrm{N} 24)$ is only marginally larger: $L 3$ $=6(2)^{\circ 2}$ and $L 3=5(1)^{\circ 2}$.

The mean square displacement amplitudes (MSDAs) along the $\mathrm{Fe}-\mathrm{N}$ and $\mathrm{Fe}-\mathrm{N} 11$ bond axis (Table 2) indicate a higher vibration amplitude of the Fe, N, and N11 atoms in the HS state and a slightly lower vibration of N21 and Fe along the $\mathrm{Fe}-\mathrm{N} 21$ axis. In the former case, these are consistent with infrared spectroscopic experiments performed on other spin

(44) Cruickshank, D. W. J. Acta Crystallogr. 1956, 9, 754.

(45) Schomaker, V.; Trueblood, K. N. Acta Crystallogr. 1968, B24, 63 

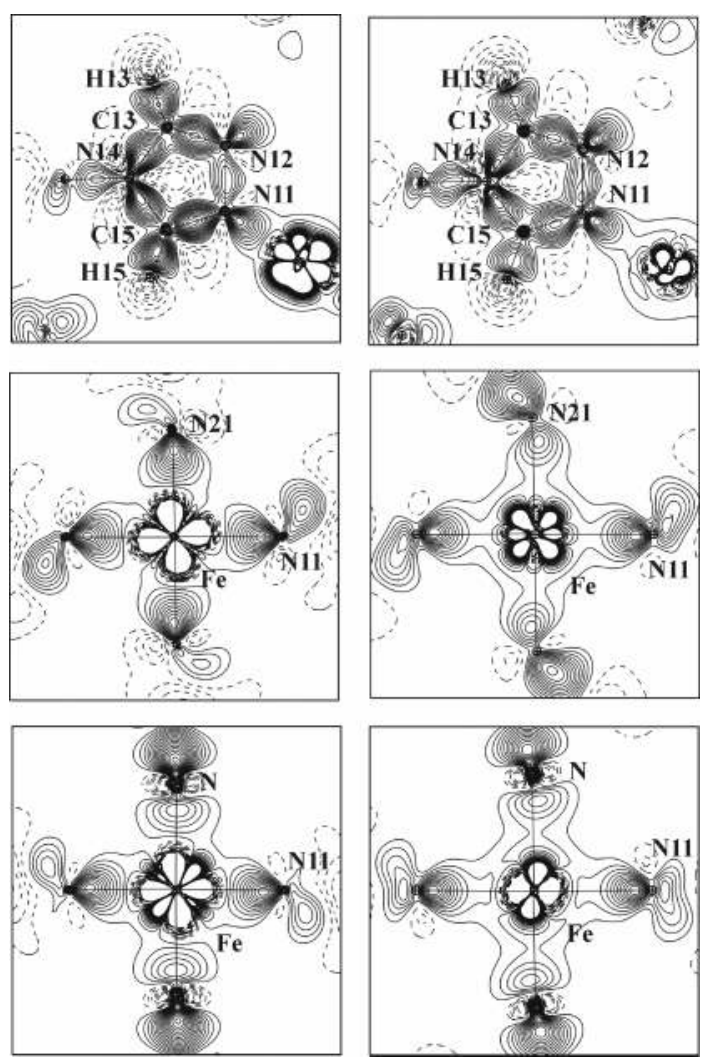

Figure 4. Static deformation density in the triazole $\mathrm{Fe}-\mathrm{N} 11-\mathrm{N} 21$ and $\mathrm{Fe}-\mathrm{N} 11-\mathrm{N}$ planes for the LS (left) and HS (right) states at $15 \mathrm{~K}$. Contour levels of 0.05 e $\AA^{-3}$; positive shown as solid lines and negative as dashed lines.

crossover materials (i.e., $\left.\mathrm{Fe}(\text { phen })_{2}(\mathrm{NCS})_{2}\right)$, revealing a large shift to lower frequencies of the $\mathrm{Fe}-\mathrm{N}$ stretching vibration on passing from LS to HS, due to a softening of the corresponding $\mathrm{Fe}-\mathrm{N}$ bond. The MSDA is related to the vibration frequency for a quantized harmonic oscillator by $\left\langle u^{2}\right\rangle=\left(h / 8 \pi^{2} \mu \nu\right)$ coth$(h v / 2 k T)$, where $\mu$ is the reduced mass and $v$ the oscillator frequency. Accordingly, the LS-to-HS vibration amplitude increase is consistent with a softening of the $\mathrm{Fe}-\mathrm{N}$ stretching force constant and a decrease in oscillator frequency. Similar conclusions have been drawn by Chandrasekhar and Bürgi for tris(dithiocarbamato)iron(III) complexes in the LS and HS states. ${ }^{46}$ The small decrease of MSDA for the Fe-N21 bond remains unexplained according to this argument.

Static Deformation Densities. The static deformation densities (difference between the multipolar ED of eq 1 and the isolated atom model) in the triazole plane in both HS and LS states are given in Figure 4. As expected, positive deformation densities show up in all the interatomic $\mathrm{N}-\mathrm{N}, \mathrm{C}-\mathrm{N}$, and $\mathrm{C}-\mathrm{H}$ bonds. The maximum of deformation is almost centered in the $\mathrm{N} 11-\mathrm{N} 12, \mathrm{~N} 14-\mathrm{N} 24, \mathrm{C} 13-\mathrm{N} 12$, and $\mathrm{C} 15-\mathrm{N} 11$ bonds. In contrast, a displacement toward N14 is observed in the C13$\mathrm{N} 14$ and $\mathrm{C} 15-\mathrm{N} 14$ ones, resulting from a polarization toward the $\mathrm{N}$ atom. A similar effect has been observed in the ED study of the btr crystal. ${ }^{30}$ The N11 and N12 lone pairs are clearly defined. Identical deformation density features are found in both spin states, with nonetheless a displacement of the deformation density in the N11-N12 bond toward N11 in the HS state.

The deformation density in the vicinity of the iron atom exhibits very different characteristics depending on the spin state.

(46) Chandrasekhar, K.; Bürgi, H. B. Acta Crystallogr. 1984, B40, 387.
In the $\mathrm{LS}$ state, in all six $\mathrm{Fe}-\mathrm{N}$ basal and axial coordination directions, negative deformation density is evidenced, interpreted as a depopulation of the $\mathrm{d}_{x^{2}-y^{2}}$ and $\mathrm{d}_{z^{2}}$ atomic orbitals with respect to the isolated $\mathrm{Fe}$ atom. Correlatively, the diagonal directions, corresponding to the $\mathrm{d}_{x y}, \mathrm{~d}_{x z}$, and $\mathrm{d}_{y z}$ orbitals, exhibit positive deformation density. Such features are characteristics of crystal field effects, which under almost $O_{h}$ symmetry split the Fe $3 \mathrm{~d}$ energy levels into $\mathrm{e}_{\mathrm{g}}\left(\mathrm{d}_{x^{2}-y^{2}}\right.$ and $\left.\mathrm{d}_{z^{2}}\right)$ and $\mathrm{t}_{2 \mathrm{~g}}\left(\mathrm{~d}_{x y}, \mathrm{~d}_{x z}\right.$, and $\mathrm{d}_{y z}$ ). The nitrogen lone pairs of the btr and NCS groups are directed toward $\mathrm{Fe}$, with the maximum of deformation density along the $\mathrm{Fe}-\mathrm{N}$ axis. The deformation density corresponding to the NCS nitrogen lone pair is lower and more diffused perpendicular to the $\mathrm{Fe}-\mathrm{N}$ axis compared to $\mathrm{N} 21$ and $\mathrm{N} 11$. The nitrogen deformation density extends to the Fe site for N, N11, and $\mathrm{N} 21$; we can anticipate a significant covalent character of the $\mathrm{Fe}-\mathrm{N}$ bonds in the LS state. The three-dimensional distribution of the Fe deformation density enlightens even more the crystal field effect (Figure 5); negative deformation density lobes are directed toward the coordinating $\mathrm{N}$ atoms in the LS state, whereas maxima of positive deformation density site at the corner of an almost regular cube centered on Fe.

In the HS state, the negative deformation density in the direction of the basal btr nitrogen atoms is retained, but it is more contracted toward Fe than in the LS state. In the axial direction, in contrast to the LS state, positive deformation density is accumulated, indicating a large electron redistribution among the Fe $3 \mathrm{~d}$ orbitals (see below). As for the LS state, the deformation density of the coordinating $\mathrm{N}$ atoms extend to the $\mathrm{Fe}$ site, a slight covalent character of the $\mathrm{Fe}-\mathrm{N}$ bonds is retained in the HS state, even-though the corresponding distances are considerably longer. The three-dimensional isosurface of the Fe deformation density (Figure 5) shows that positive contributions are directed only in the diagonal directions of the basal plane (corresponding to the $\mathrm{d}_{x y}$ orbital) and in the $z$ direction (toward NCS), contrasting with the LS state. In addition, the negative deformation density is more diffuse, with a lower directional behavior; this is probably due to the HS state having longer $\mathrm{Fe}-\mathrm{N}$ bond distances.

Orbital Population Analysis. The elucidation of the groundstate and low-lying excited-state electronic configurations of organometallic complexes is of major importance. Many theoretical calculations with various degrees of approximation (multiconfigurational, Moller-Plesset perturbation) have dealt with iron(II) porphyrin and phthalocyanine, for instance. In the case of spin crossover materials, the singlet ${ }^{1} \mathrm{~A}_{1}$ and quintet ${ }^{5} \mathrm{~T}_{2}$ electron configurations have been assigned to the LS and HS states for iron(II) in perfectly octahedral surrounding, respectively; the triplet states are considered to be involved through intersystem crossing in the light-induced process (LIESST). The multipolar modeling of the Fe deformation density allows a direct calculation of the $3 \mathrm{~d}$ orbital populations, ${ }^{47}$ if the metal and ligand orbitals do not strongly overlap. As discussed above, this is not rigorously valid for $\mathrm{Fe}(\mathrm{btr})_{2}(\mathrm{NCS})_{2} \cdot \mathrm{H}_{2} \mathrm{O}$ since significant $\mathrm{Fe}-\mathrm{N}$ covalent character might be present, but it is nevertheless a good approximation. The Fe $3 \mathrm{~d}$ orbital populations derived from our multipolar modeling are given in Table 3.

The populations calculated for the LS state are characteristic of $\mathrm{Fe}^{\mathrm{II}}\left(3 \mathrm{~d}^{6}\right)$ with an almost $\mathrm{t}_{2 \mathrm{~g}}{ }^{6} \mathrm{e}_{\mathrm{g}}{ }^{0}$ electron configuration. The

(47) Holladay, A.; Leung P.; Coppens, P. Acta Crystallogr. 1983, A39, 377. 

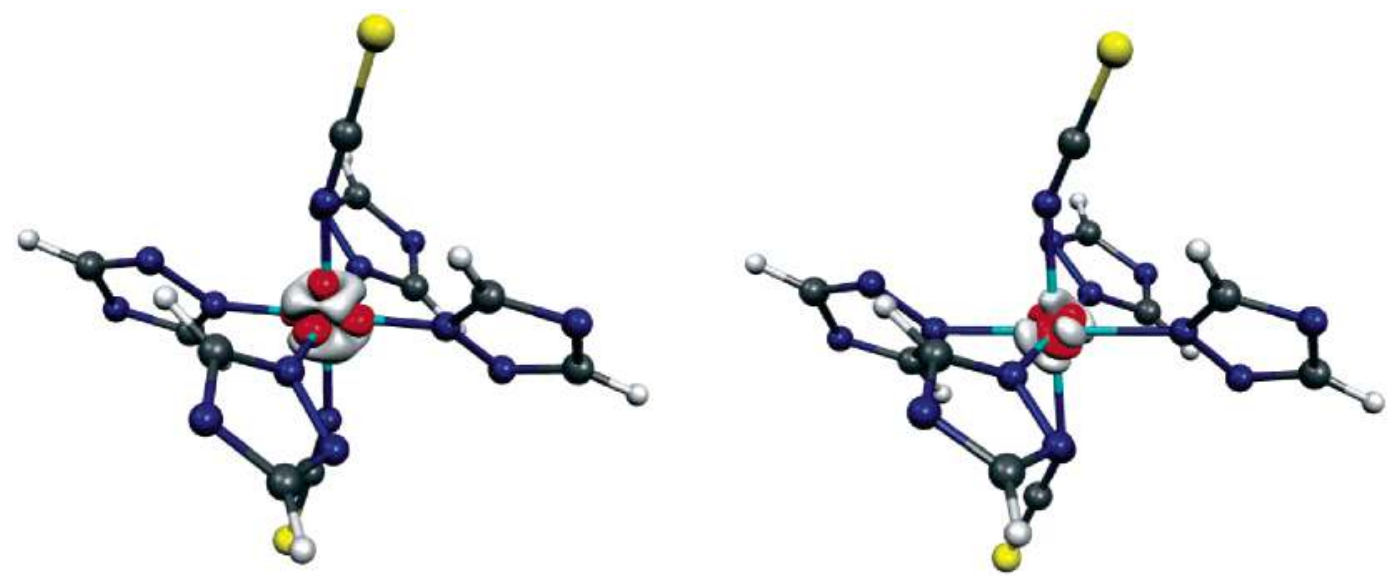

Figure 5. Static deformation density of iron in the LS (left) and HS (right) states at $15 \mathrm{~K}$ (isosurface of $0.2 \mathrm{e} \AA^{-3}$, positive shown in gray, negative in red).

Table 3. 3d Atomic Orbital Populations of Iron in LS and HS States. the Crystal Field Hypothesis Corresponds to Pure Octahedral Symmetry

\begin{tabular}{|c|c|c|c|c|c|c|}
\hline & $d x^{2}-y^{2}$ & $\mathrm{~d}_{z^{2}}$ & $d_{x y}$ & $d_{x z}$ & $d_{y z}$ & $\begin{array}{c}\text { total } 3 d \\
\text { population }\end{array}$ \\
\hline LS state & 0.40 & 0.20 & 1.50 & 2.22 & 1.94 & 6.26 \\
\hline HS state & 0.95 & 1.49 & 1.59 & 0.94 & 1.17 & 6.14 \\
\hline LS crystal field hypothesis & 0 & 0 & 2 & 2 & 2 & 6 \\
\hline HS crystal field hypothesis & 1 & 1 & 1.33 & 1.33 & 1.33 & 6 \\
\hline
\end{tabular}

crystal field destabilized $\mathrm{d}_{x^{2}-y^{2}}$ and $\mathrm{d}_{z^{2}}$ orbitals exhibit nevertheless a significant population, attributed to donation from the highest occupied molecular orbitals of the NCS and btr ligands and the onset of slight $\mathrm{Fe}-\mathrm{N}$ covalent interactions in addition to the electrostatic coordination bond. These btr and NCS molecular orbitals have large $\sigma$ character on the peripheral $\mathrm{N}$ atoms and accordingly allow high $\sigma$ overlap with the $\mathrm{Fe} \mathrm{d}_{z^{2}}$ and $\mathrm{d}_{x^{2}-y^{2}}$ orbitals for NCS and btr, respectively. According to the populations of the $\mathrm{d}_{x^{2}-y^{2}}$ and $\mathrm{d}_{z^{2}}$ orbitals, the amount of electron donation from the two ligands is in the same range, 0.1 e by each NCS group and 0.1 e by each triazole ring. By comparison with a purely LS crystal field hypothesis, the population of the $d_{x y}$ orbital is less populated than expected, due to $\pi$ back-bonding to the btr lowest unoccupied molecular orbitals. These latter have a strong $\pi^{*}$ character and can overlap with the iron $\mathrm{d}_{x y}$ orbital. As judged by the orientation of the btr ligand with respect to the Fe basal plane, this overlap is however not optimum. The overall electron donation balance resulting from $\sigma$ donation and $\pi$ back-bonding interactions amounts to +0.26 e on Fe, according to its $3 \mathrm{~d}$ electron population of 6.26. The LS Fe populations can be compared to those derived for iron(II) phthalocyanine (FePc), ${ }^{48}$ iron(II) tetraphenylporphyrin (FeTPP), ${ }^{49}$ and iron(II) bis(pyridine)(meso-tetraphenylporphinato) $\left(\mathrm{FeTPP}(\mathrm{Py})_{2}\right),{ }^{50}$ with $S=1, S=1$, and $S=0$ ground spin states, respectively, and for which the $\mathrm{d}_{x^{2}-y^{2}}$ orbital is also populated due to $\sigma$ donation from the porphyrin and phthalocyanine ligands. The $\mathrm{d}_{x^{2}-y^{2}}$ orbital populations follow the $\mathrm{Fe}-\mathrm{N}$ bond distances in the series FeTPP(Py $)_{2}(0.35$ e), FeTPP $(0.43$ e), and FePc (0.70 e) for bond distances of 2.001(1), 1.967(2), and 1.928(1) $\AA$, respectively. The $\mathrm{d}_{x^{2}-y^{2}}$ orbital population found in the present case is compatible with this evolution and the

(48) Coppens, P.; Li, L. J. Chem. Phys. 1984, 81, 1983.

(49) Tanaka, K.; Elkaim, E.; Liang, L.; Zhu, N. J.; Coppens, P.; Landrum, J. J. Chem. Phys. 1986, 84, 6969.

(50) Li, N.; Coppens, P.; Landrum, J. Inorg. Chem. 1988, 27, 482.
1.9685(5) and 1.9730(5) $\AA \mathrm{Fe}-\mathrm{N} 11$ and $\mathrm{Fe}-\mathrm{N} 21$ bond distances. To summarize, the LS $3 \mathrm{~d}$ orbital populations are consistent with a purely LS crystal field hypothesis in ${ }^{1} \mathrm{~A}_{1}$ electron configuration, in agreement with the close to $0 \mathrm{~mm}$ $\mathrm{s}^{-1}$ quadrupole splitting of the Mössbauer spectrum. ${ }^{25}$

In the metastable HS state, all 3d orbitals are more uniformly populated, ranging from 0.94 to 1.59 e each. This distribution is more consistent with a HS crystal field hypothesis, where the deviation from purely crystal field effect is due to $\sigma$ donation and $\pi$ back-bonding with the coordinating ligands. The overall electron donation from the six ligands is lower $(0.14 \mathrm{e})$ than in the LS state, as judged by the $3 \mathrm{~d}$ valence population of 6.14 for Fe. It appears that NCS is more $\sigma$ donor than in the LS state, the $\mathrm{d}_{z^{2}}$ orbital gaining 0.25 e from each NCS group. This is surprising since the $\mathrm{Fe}-\mathrm{N}$ bond distance is longer in the HS state, but inspection of Figure 4 suggests that, in the LS state, electron repulsion overcomes electron pairing in this bond. The $\mathrm{d}_{x^{2}-y^{2}}$ orbital population does not show any $\sigma$ donation from the btr groups, being close to that obtained in the purely crystal field hypothesis. On the other side, the $\mathrm{d}_{x y}$ orbital exhibits a high population, difficult to rationalize in $O_{h}$ symmetry in terms of $\pi$ back-bonding. Alternatively, this could indicate that the real interaction symmetry is reduced from $O_{h}$ to almost $D_{4 h}$, the $3 \mathrm{~d}$ energy levels being split into $\mathrm{e}_{\mathrm{g}}\left(\mathrm{d}_{x z}, \mathrm{~d}_{y z}\right), \mathrm{b}_{2 \mathrm{~g}}\left(\mathrm{~d}_{x y}\right), \mathrm{a}_{1 \mathrm{~g}}$ $\left(\mathrm{d}_{z^{2}}\right)$, and $\mathrm{b}_{1 \mathrm{~g}}\left(\mathrm{~d}_{\left.x^{2}-y^{2}\right)}\right)$ under tetragonal field. The occupation difference of the $d_{x y}, d_{x z}$, and $d_{y z}$ orbitals supports this splitting. Under such circumstances, the experimental orbital population would indicate a ${ }^{5} \mathrm{~B}_{2 \mathrm{~g}}$ ground quintet state. This symmetry breaking has an interaction origin and is also reflected in the molecular structure, the $\mathrm{FeN}_{6}$ octahedron of $\mathrm{Fe}(\mathrm{btr})_{2}(\mathrm{NCS})_{2}$. $\mathrm{H}_{2} \mathrm{O}$ being very regular in the LS and HS states, but with shorter $\mathrm{Fe}-\mathrm{N}$ coordination distances. Such an assignment needs to be confirmed on other spin transition systems for which the NCS groups are located in the trans position, like in the present situation. It has been argued that slight modifications of the $\mathrm{Fe}-\mathrm{N}$ axial and basal bond lengths play a key role in the spin multiplicity and electronic configuration of the ground state of iron porphyrin and phthalocyanine ${ }^{51}$ through the relative stabilization of the $\sigma$ acceptor $\mathrm{d}_{x^{2}-y^{2}}$ orbital. A clear assignment of the $\mathrm{HS} \mathrm{Fe}^{\mathrm{II}}$ electron configuration would require complementary quantum mechanical calculations of this system. The $D_{4 h}$ symmetry of the coordination sphere characterized from

(51) Silver, J.; Marsh, P. J.; Symons, M. C. R.; Svistunenko, D. A.; Frampton, C. S.; Fern, G. R. Inorg. Chem. 2000, 39, 2874. 
Table 4. Topological Properties at the Bond Critical Points ${ }^{a}$

\begin{tabular}{|c|c|c|c|c|c|c|c|c|c|}
\hline bond & $d x-y$ & $d_{x-C P}$ & $d_{C P-Y}$ & $\rho\left(\vec{r}_{\mathrm{CP}}\right)$ & $\nabla^{2} \rho\left(r_{C P}\right)$ & $\epsilon$ & $\begin{array}{l}G\left(r_{\mathrm{CP} P}\right) / \\
\rho\left(r_{\mathrm{CP} P}\right)\end{array}$ & $V\left(\vec{r}_{\mathrm{CP}}\right)$ & $H\left(\vec{r}_{\mathrm{CP}}\right)$ \\
\hline \multicolumn{10}{|c|}{ LS State } \\
\hline $\mathrm{Fe}-\mathrm{N}$ & $1.9498(5)$ & 0.945 & 1.007 & 0.62 & 8.03 & 0.26 & 1.19 & -2395 & -460 \\
\hline $\mathrm{Fe}-\mathrm{N} 11$ & $1.9730(5)$ & 0.949 & 1.028 & 0.66 & 7.70 & 0.26 & 1.15 & -2584 & -585 \\
\hline $\mathrm{Fe}-\mathrm{N} 21$ & $1.9685(5)$ & 0.941 & 1.029 & 0.66 & 7.82 & 0.29 & 1.16 & -2591 & -577 \\
\hline $\mathrm{N}-\mathrm{C}$ & $1.1753(7)$ & 0.739 & 0.437 & 2.96 & -6.90 & 0.00 & & & \\
\hline $\mathrm{C}-\mathrm{S}$ & $1.6405(5)$ & 0.779 & 0.861 & 1.49 & -4.93 & 0.00 & & & \\
\hline N14-N24 & $1.3701(6)$ & 0.684 & 0.684 & 2.28 & -5.40 & 0.00 & & & \\
\hline N14-C15 & $1.3655(7)$ & 0.821 & 0.545 & 2.14 & -17.68 & 0.15 & & & \\
\hline $\mathrm{N} 14-\mathrm{C} 13$ & $1.3675(7)$ & 0.814 & 0.555 & 2.14 & -16.88 & 0.09 & & & \\
\hline $\mathrm{C} 13-\mathrm{N} 12$ & $1.3061(7)$ & 0.549 & 0.762 & 2.43 & -20.15 & 0.19 & & & \\
\hline C15-N11 & $1.3092(7)$ & 0.554 & 0.758 & 2.54 & -24.38 & 0.24 & & & \\
\hline $\mathrm{N} 11-\mathrm{N} 12$ & $1.3970(6)$ & 0.699 & 0.695 & 2.14 & -1.02 & 0.03 & & & \\
\hline Hw $\cdots$ N12 & $2.35(2)$ & 0.879 & 1.436 & 0.07 & 1.45 & 0.07 & 1.10 & -139 & 64 \\
\hline \multicolumn{10}{|c|}{ HS State } \\
\hline $\mathrm{Fe}-\mathrm{N}$ & $2.1310(9)$ & 1.061 & 1.069 & 0.45 & 6.37 & 0.01 & 1.13 & -1506 & -168 \\
\hline $\mathrm{Fe}-\mathrm{N} 11$ & $2.171(1)$ & 1.064 & 1.108 & 0.43 & 5.61 & 0.09 & 1.07 & -1378 & -173 \\
\hline $\mathrm{Fe}-\mathrm{N} 21$ & $2.1647(9)$ & 1.062 & 1.102 & 0.44 & 5.81 & 0.09 & 1.08 & -1430 & -181 \\
\hline $\mathrm{N}-\mathrm{C}$ & 1.179(1) & 0.739 & 0.444 & 3.00 & -12.26 & 0.00 & & & \\
\hline $\mathrm{C}-\mathrm{S}$ & $1.634(1)$ & 0.777 & 0.855 & 1.56 & -5.78 & 0.00 & & & \\
\hline N14-N24 & $1.374(1)$ & 0.686 & 0.686 & 2.32 & -6.17 & 0.05 & & & \\
\hline N14-C15 & $1.367(1)$ & 0.810 & 0.557 & 2.12 & -14.11 & 0.13 & & & \\
\hline $\mathrm{N} 14-\mathrm{C} 13$ & $1.374(1)$ & 0.822 & 0.552 & 2.08 & -13.21 & 0.08 & & & \\
\hline $\mathrm{C} 13-\mathrm{N} 12$ & $1.305(1)$ & 0.537 & 0.769 & 2.40 & -18.69 & 0.13 & & & \\
\hline C15-N11 & $1.312(1)$ & 0.534 & 0.776 & 2.36 & -17.10 & 0.13 & & & \\
\hline N11-N12 & $1.398(1)$ & 0.702 & 0.694 & 2.16 & 0.04 & 0.05 & & & \\
\hline $\mathrm{Hw} \cdots \mathrm{N} 12$ & $2.31(1)$ & 0.807 & 1.400 & 0.10 & 1.61 & 0.08 & 0.92 & -190 & 53 \\
\hline
\end{tabular}

${ }^{a} \epsilon$ is the bond ellipticity. $V$ and $H$ are given in $\mathrm{kJ} \mathrm{mol}^{-1} \AA^{-3}, \rho\left(\vec{r}_{\mathrm{CP}}\right)$ in e $\AA^{-3}$, and $\nabla^{2} \rho\left(\vec{r}_{\mathrm{CP}}\right)$ in e $\AA^{-5}$. The Abramov ${ }^{53}$ approximation for deriving the local energy densities is valid at the BCP for weak bonds; $G, G / \rho, V$, and $H$ are reported for $\mathrm{Fe}-\mathrm{N}$ and $\mathrm{H} \cdots \mathrm{N}$ bonds solely.

the present ED analysis is in line with the nonzero value of the quadrupole splitting of the Mössbauer spectrum in the HS state. ${ }^{25}$

Topological Analysis of the Electron Density. The topological analysis of the ED has proved to be an appropriate approach to quantitatively analyze chemical bonding in ionic crystals and molecular solids. According to the formalism developed by Bader, a chemical bond is uniquely characterized by the presence of a line of maximum ED joining two bonded atoms (a bond path) on which lies a bond critical point (BCP). ${ }^{52}$ The sign of the laplacian of the ED, $\nabla^{2} \rho(r)$, points out regions of charge accumulation $\left(\nabla^{2} \rho(r)<0\right)$ and charge depletion $\left(\nabla^{2} \rho\right.$ $(r)>0)$. A direct link has been proposed between the regions of large negative laplacian and the concept of electron pairs in the atomic valence shell; these are called valence shell charge concentrations (VSCCs). The behavior of the ED and laplacian at a BCP allows a distinction to be made between closed-shell and shared-shell interactions. It has been suggested that, in the case of transition metal, the ED and laplacian are not well adapted descriptors for unambiguously characterizing metalligand bonding. In such cases, kinetic $(G(r))$ and potential $(V(r))$ energy densities, evaluated through the Abramov approximation, ${ }^{53}$ which is valid only for low ED at $\mathrm{CP}$, allow a better classification, ${ }^{54,55}$ covalent character being associated with an excess of potential energy over the kinetic energy densities. The topological properties of the ED in $\mathrm{Fe}(\text { btr })_{2}(\mathrm{NCS})_{2} \cdot \mathrm{H}_{2} \mathrm{O}$ have been derived using Newprop. ${ }^{56,57}$ The topological properties at the BCPs are given in Table 4.

(52) Bader, R. F. W.; Essen, H. J. Chem. Phys. 1984, 80, 1943.

(53) Abramov, Y. A. Acta Crystallogr. 1997, A53, 264.

(54) Cremer, D.; Kraka, E. Croat. Chem. Acta 1984, 57, 1259.

(55) Cremer, D.; Kraka, E. Angew Chem., Int. Ed. Engl. 1984, 23, 627.

(56) Souhassou, M.; Blessing, R. H. J. Appl. Crystallogr. 1999, 32, 210.

(57) Katan, C.; Rabiller, P.; Lecomte, C.; Guezo, M.; Oison, V.; Souhassou, M. J. Appl. Crystallogr. 2003, 36, 65 .
The EDs at all the $\mathrm{Fe}-\mathrm{N}$ BCPs mirror the differences in bond distances, with systematically higher values in the LS state. An exception is the $\mathrm{Fe}-\mathrm{NCS}$ bond in the LS state, which is shorter than the $\mathrm{Fe}-\mathrm{N} 11$ and $\mathrm{Fe}-\mathrm{N} 21$ ones with nonetheless a lower ED. The BCPs are furthermore not well centered in the bond but systematically displaced toward $\mathrm{Fe}$ due to the high electron concentration of the $\mathrm{N}$ lone pairs. More insights into the covalent and ionic character of the $\mathrm{Fe}-\mathrm{N}$ chemical bonds can be gained from the energetic properties at the BCPs. For $\mathrm{Fe}-\mathrm{N}$, the potential energy density is dominating in the total energy density; the density normalized kinetic energy density $G(r) / \rho(r)$ is in slight excess of unity, indicating a significant shared-shell component of the $\mathrm{Fe}-\mathrm{N}$ chemical bond, stronger than what is observed for $\mathrm{Fe}-\mathrm{O}$ and $\mathrm{Fe}-\mathrm{C}$ bonds. ${ }^{58,59}$ Together, all these ED descriptors correlate with a significant covalent character of the coordination $\mathrm{Fe}-\mathrm{N}$ bonds, more pronounced in the LS state, in agreement with the structural features. Also based on these energetic arguments, the covalent interaction is lower in the Fe-NCS bond in both spin states.

For the btr ligand, the HS-LS difference in ED is within the standard deviation we can estimate on our ED; the only exception is the $\mathrm{C} 15-\mathrm{N} 11$ bond. All $\mathrm{N}-\mathrm{N}$ bonds show similar characteristics of the ED: the BCP is almost centered in the bond, the laplacian of the ED is negative but small, and the ellipticity is lower than 0.1 , as observed for single bonds. The ED laplacian and ellipticity are higher in the C13-N12 and C15-N11 bonds than in the N14-C15 and N14-C13. The nonzero values of the ellipticity in all $\mathrm{C}-\mathrm{N}$ bonds indicate an electron delocalization over the four bonds, with a higher $\pi$

(58) Macchi, P.; Garlaschelli, L.; Sironi, A. J. Am. Chem. Soc. 2002, 124, 14173 (59) Overgaard, J.; Larsen, F. K.; Schiott, B.; Iversen, B. B. J. Am. Chem. Soc. 2003, 125,11088 . 

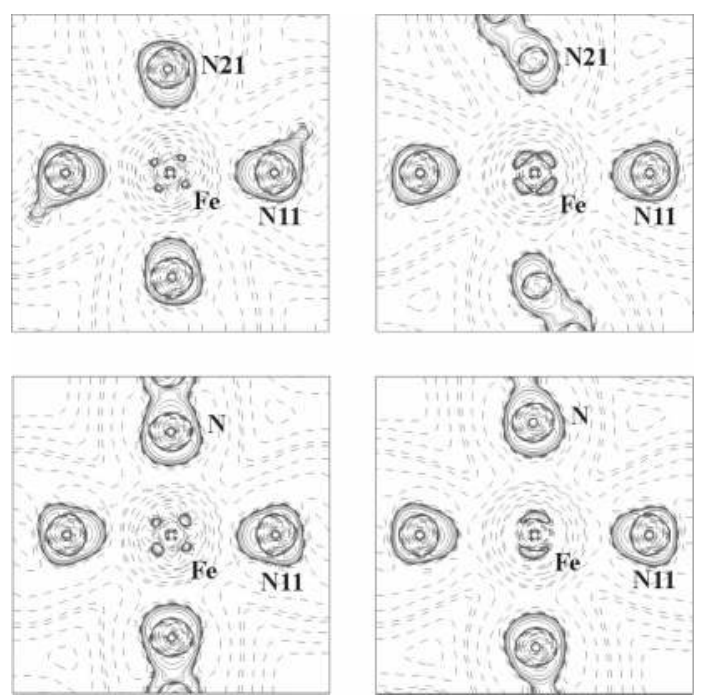

Figure 6. Laplacian distribution in the $\mathrm{Fe}-\mathrm{N} 11-\mathrm{N} 21$ and $\mathrm{Fe}-\mathrm{N}-\mathrm{N} 11$ planes for the LS (left) and HS (right) states. Contour levels at $10^{n}, 2 \times$ $10^{n}, 4 \times 10^{n}$, and $8 \times 10^{n}$ e $\AA^{-5}(n=-3,-2,-1,0,1)$; positive shown as solid lines and negative as dashed lines.

character of $\mathrm{C} 13-\mathrm{N} 12$ and $\mathrm{C} 15-\mathrm{N} 11$. Accordingly, the main mesomeric form of the triazole ring could be depicted as<smiles>Nn1cnnc1</smiles>

For the NCS group, the $\mathrm{ED}$ is much higher in the $\mathrm{C}-\mathrm{N}$ bond, which is formally a triple bond. The value of the ellipticity is zero in both $\mathrm{C}-\mathrm{N}$ and $\mathrm{C}-\mathrm{S}$ bonds, due to the cylindrical constraint applied during the refinement. There is no clear differentiation between the HS and LS states by comparison of the topological properties at the BCPs, the ED being marginally higher in the HS state.

In the basal $\mathrm{FeN}_{4}$ plane and in the $\mathrm{Fe}-\mathrm{NCS}$ axial direction in both spin states, the laplacian distribution (Figure 6) shows maxima close to $\mathrm{N}$ and directed toward $\mathrm{Fe}$, corresponding to well-defined VSCCs. These VSCCs correspond to electron concentration of the $\mathrm{N}$ lone pairs in the Lewis concept of electron pairs. In contrast, the laplacian distribution in the vicinity of $\mathrm{Fe}$ shows very different characteristics, depending on the spin state (Figure 7). In the LS state, the laplacian adopts a cubic shape with well-defined maxima of $-\nabla^{2} \rho$ at the vertices of the cube. Such a distribution is not uncommon and has been characterized in $\mathrm{Cr}(\mathrm{CO})_{6}$, for instance. ${ }^{60}$ Further examples of the correlation between the laplacian distribution and crystal field effects have been given in the literature. ${ }^{61}$ In the present case, the laplacian distribution results from strong ligand field effects, with electron deficit along the face directions and accumulation in the direction of the vertices of the cube. It is the signature of the Fe LS state. In the HS state, maxima of $-\nabla^{2} \rho$ are located along the $z$ axis and along the diagonal directions of the basal plane. These maxima are fully consistent with the $3 \mathrm{~d}$ orbital populations described above.

Interlayer Contacts. The crystal structure of $\mathrm{Fe}(\mathrm{btr})_{2}(\mathrm{NCS})_{2} \cdot$ $\mathrm{H}_{2} \mathrm{O}$ indicates the presence of $\mathrm{N} 22 \cdots \mathrm{Hw}-\mathrm{Ow}$ hydrogen bonds involved in interlayer contacts (Figure 1). The total ED (Figure 8) shows indeed bridges of ED in the corresponding interlayer region, furthermore topologically characterized by a BCP. Values of the ED and laplacian at the BCP are identical in the two spin states (Table 4); there is no clear modification of the hydrogen bond strength upon the spin transition. These hydrogen bonds are responsible for the onset of weakly cooperative interactions along the crystallographic $a$ direction.

Fragment Charges and Molecular Electrostatic Potential. The ED has been integrated over the atomic basins defined by the zero flux surfaces of the gradient field, yielding atomic charges and volumes (Table 5). This concept of atomic charges relies on the ED solely and is therefore rather model independent. The LS and HS states present some similarities in the charge distribution over the different fragments of the structure. The iron atom is positively charged, the NCS group is negative, and the btr ligand is slightly positive. However, these charges are less than the formal $\mathrm{Fe}^{2+}$ and $\mathrm{NCS}^{-}$. The thiocyanate ligand shows high electron polarization effects: the negative charge is mostly localized on the $\mathrm{N}$ atom, and the central carbon atom is positively charged. As for btr, the coordinating $\mathrm{N}$ atoms (N11 and N21) are slightly more negative than the non-coordinating ones (N12 and N22), resulting from the interaction with Fe. On going from the LS to the HS state, electron redistribution is evidenced: Fe and btr are more positive, whereas NCS is more negative. Accordingly, the $\mathrm{Fe}-\mathrm{NCS}$ and $\mathrm{Fe}-$ btr interactions are slightly more covalent in the LS state, in agreement with the topological analysis discussed above. A similar conclusion has been drawn by Paulsen et al. ${ }^{62}$ from ab initio calculations on $\mathrm{Fe}$ (II) complexes with substituted tris(pyrazolyl) ligands; they reported an Fe charge increase by $0.176-0.186 \mathrm{e}$.

The increase of atomic volumes upon the LS-to-HS transition parallels the structural modifications and especially the $\mathrm{Fe}-\mathrm{N}$ bond elongation. The NCS volume increases by as much as $7.8 \AA^{3}$, and the $\mathrm{Fe}$ atomic volume increases by $2.39 \AA^{3}$,
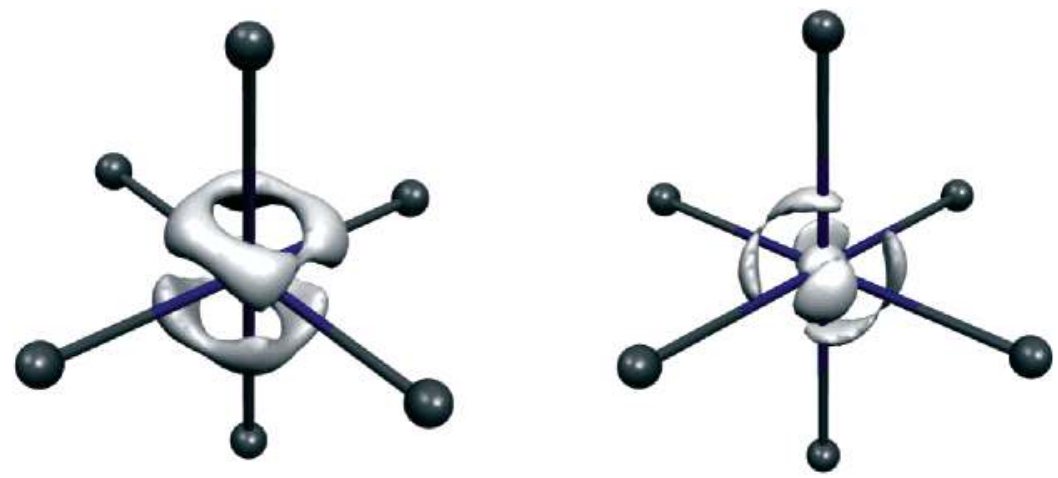

Figure 7. Laplacian distribution of iron in the LS (left) and HS (right) states (isosurface of $-500 \mathrm{e} \AA^{-5}$ ). Only the negative surface is displayed. 


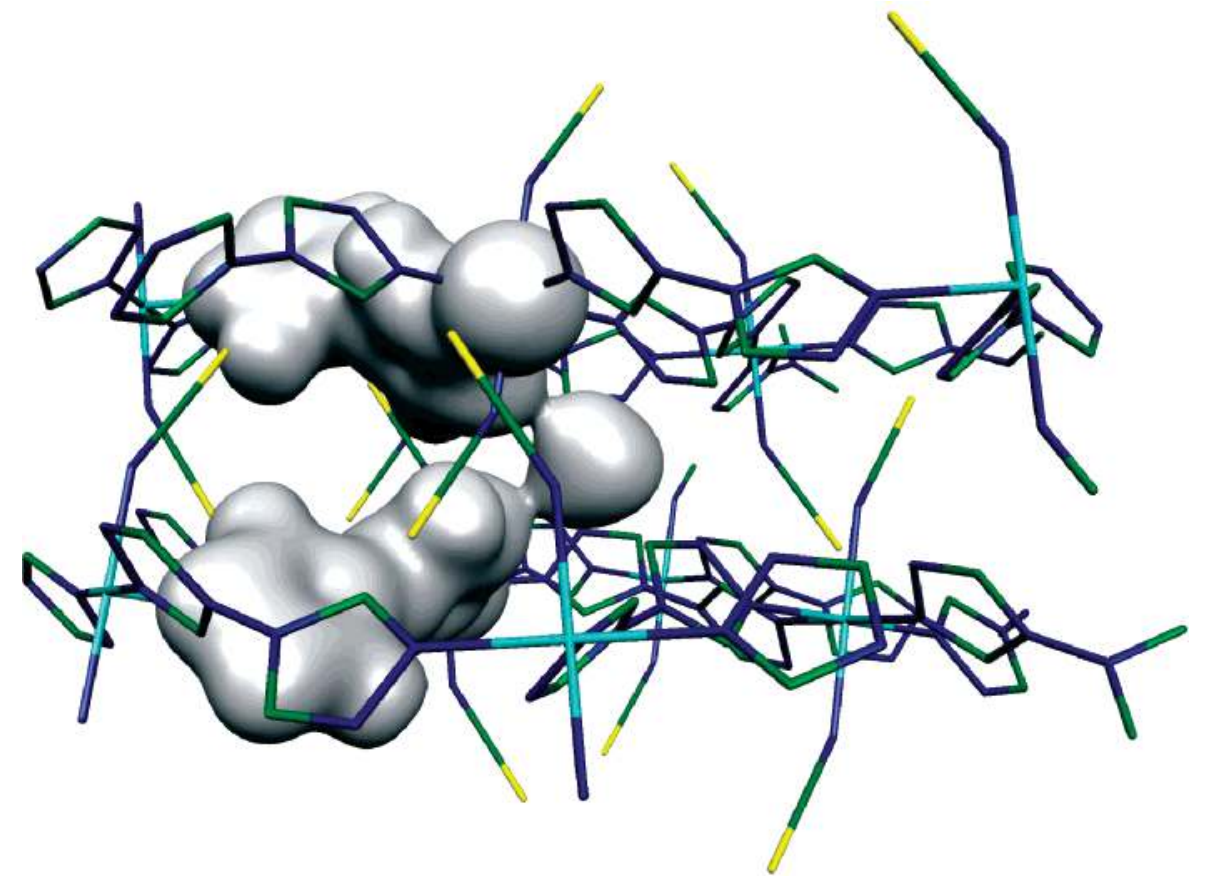

Figure 8. Total electron density in the HS state showing the interlayer hydrogen bonds (isosurface of 0.08 e $\AA^{-3}$ ).

Table 5. Topological Charges and Volumes from Numerical Integration of the ED over the Atomic Basins ${ }^{a}$

\begin{tabular}{lrrrrc}
\hline & \multicolumn{3}{c}{ LS } & & \multicolumn{2}{c}{$H S$} \\
\cline { 2 - 3 } \cline { 5 - 6 } & \multicolumn{1}{c}{$Q_{\Omega}$} & \multicolumn{1}{c}{$V_{\Omega}$} & & $Q_{\Omega}$ & $V_{\Omega}$ \\
\hline $\mathrm{Fe}$ & 0.63 & 8.618 & & 0.74 & 11.013 \\
$\mathrm{~N}$ & -1.16 & 17.777 & & -1.28 & 20.459 \\
$\mathrm{C}$ & 0.71 & 12.811 & & 0.66 & 14.006 \\
$\mathrm{~S}$ & -0.29 & 40.695 & & -0.27 & 44.627 \\
$\mathrm{NCS}$ & -0.74 & 71.283 & & -0.89 & 79.092 \\
$\mathrm{~N} 11$ & -0.60 & 11.631 & & -0.70 & 13.666 \\
$\mathrm{~N} 12$ & -0.46 & 14.568 & & -0.57 & 15.147 \\
$\mathrm{~N} 21$ & -0.59 & 11.717 & & -0.71 & 13.235 \\
$\mathrm{~N} 22$ & -0.43 & 14.699 & & -0.54 & 15.460 \\
$\mathrm{btr}$ & 0.18 & 138.863 & & 0.25 & 138.26 \\
$\mathrm{H} \mathrm{H}_{2} \mathrm{O}$ & -0.09 & 27.283 & -0.02 & 30.757 \\
\hline
\end{tabular}

a The total topological charge $\left(Q_{\Omega}\right)$ and volume $\left(V_{\Omega}\right)$, summed over the unit cell, are $Q_{\mathrm{LS}}=938.32 \mathrm{e}, V_{\mathrm{LS}}=1824.8 \AA^{3}, Q_{\mathrm{HS}}=938.45 \mathrm{e}$, and $V_{\mathrm{HS}}$ $=1905.9 \AA^{3}$, corresponding to mean errors of $0.3 \%$ and $1.6 \%$ due to the integration procedure on $Q$ and $V$, respectively.

comparable with the $3.25 \AA^{3}$ value calculated from the expansion of the $\mathrm{FeN}_{6}$ polyhedra. ${ }^{63}$

The molecular electrostatic potential has been calculated analytically from the modeled multipolar total ED for a (triazole $)_{4}(\mathrm{NCS})_{2}$ cluster removed from the crystal lattice using ELECTROS ${ }^{64,65}$ (Figure 9). In both spin states, the triazole group generates a positive electrostatic potential, in agreement with its global positive charge. On the other hand, the NCS group generates a strong electronegative potential in its surroundings, stronger on the $\mathrm{N}$ side than on the $\mathrm{S}$ one, in accordance with the electron polarization discussed above and larger charge accumulation on N. In the LS state, the NCS electronegative potential is more localized on the $\mathrm{N}$ and $\mathrm{S}$ terminal atoms than in the HS state, due to the larger $\mathrm{C}$ positive charge. The additive contributions of two trans NCS groups in the axial directions and four triazole rings in the equatorial plane result in a cavity of negative electrostatic potential where the Fe atom sites. In view of this electrostatic potential and the fragment charges discussed in the previous section, NCS behaves as the key element of the crystal field. This is particularly evident in the HS state, where the shape of the negative electrostatic potential around $\mathrm{Fe}$ is characterized by an elongation in the NCS direction. In the LS state, the negative potential cavity is considerably compressed with respect to the HS state.

\section{Conclusion}

We have analyzed in a quantitative way the experimental ED distribution of a molecular metastable state for the first time. These results show that the quality of the refined ED model is comparable to those usually achieved on ground-state systems and proved to be very promising. In the present situation, appropriate experimental conditions and procedures have been attained to face the difficulties intrinsically attached to metastable states, namely the relaxation toward the thermodynamically favorable ground state. The comparison of the ED properties between the ground LS state and the metastable HS state of the spin crossover compound $\mathrm{Fe}(\mathrm{btr})_{2}(\mathrm{NCS})_{2} \cdot \mathrm{H}_{2} \mathrm{O}$ has been performed using the quantum theory of atoms in molecules, which offers a broad view of the interactions, and especially the coordination $\mathrm{Fe}-\mathrm{N}$ interactions. The $\mathrm{Fe} 3 \mathrm{~d}$ orbital populations, derived from the multipolar description of the deformation density, are consistent with LS $\left(\mathrm{t}_{2 \mathrm{~g}}{ }^{6} \mathrm{e}_{\mathrm{g}}{ }^{0}\right)$ and $\mathrm{HS}\left(\mathrm{t}_{2 \mathrm{~g}}{ }^{4} \mathrm{e}_{\mathrm{g}}{ }^{2}\right)$ electron configurations. These populations are consistent with a ${ }^{1} \mathrm{~A}_{1}$ electron configuration in the LS state, but they also indicate a decrease of symmetry to almost $D_{4 h}$ in the metastable HS state,

(60) Hall, M. B.; Hall, P. B. Studies of Electron Distributions in Molecules and Crystals; Transactions of the American Crystallographic Association 24, American Crystallographic Association: Buffalo, NY, 1990.

(61) Cortes-Guzman, F.; Bader, R. F. W. Coord. Chem. Rev. 2005, 249, 633.

(62) Paulsen, H.; Wolny, J. A.; Trautwein, A. X. Monatsch. Chem. 2005, 136, 1107.

(63) Balic Zunic, T.; Vickovic, I. J. Appl. Crystallogr. 1996, 29, 305.

(64) Ghermani, N. E.; Bouhmaida, N.; Lecomte, C. Acta Crystallogr. 1993, A49, 781

(65) Bouhmaida, N.; Ghermani, N. E.; Lecomte, C.; Thalal, A. Acta Crystallogr. 1997, A53, 556 

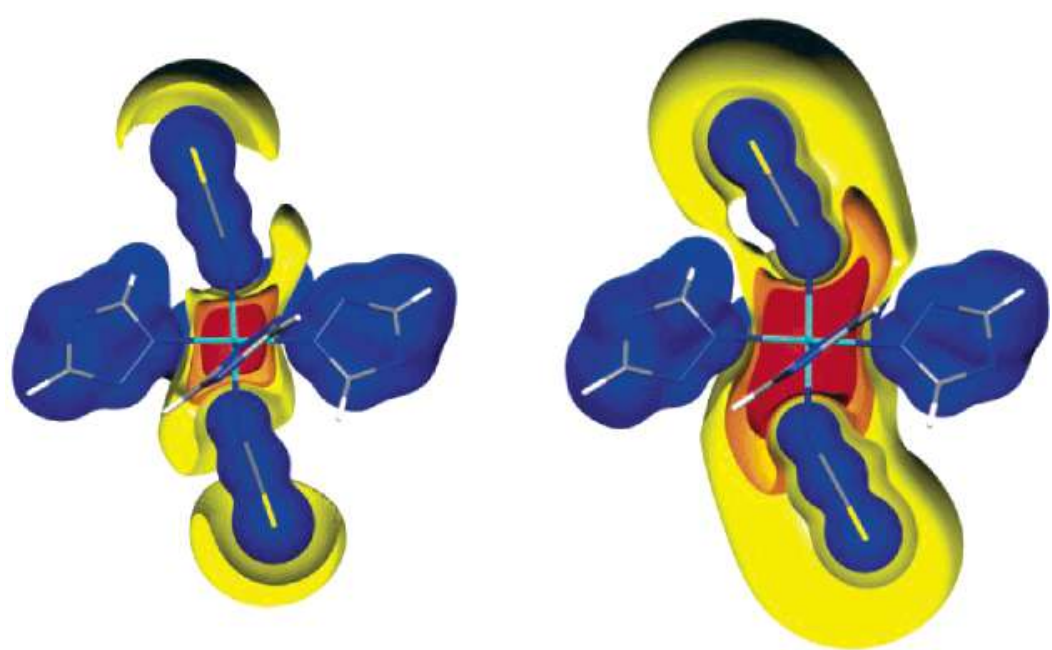

Figure 9. Isosurface of molecular electrostatic potential in the LS (left) and HS (right) states calculated for a (triazole) $)_{4}(\mathrm{NCS})_{2}$ cluster. Isosurfaces of +0.1 $\mathrm{e} \AA^{-1}$ are shown in blue and $-0.3,-0.2$, and -0.1 e $\AA^{-1}$ from red to yellow.

with an electron configuration which would be better described as ${ }^{5} \mathrm{~B}_{2 \mathrm{~g}}$. This symmetry decrease is in line with the coordination bond distances.

Large modifications of the electronic properties are observed on going from LS to HS, which parallels the structural features; a clear distinction can be made between the bonding behaviors of NCS and btr. The NCS group exhibits a high negative fragment charge further polarized toward the more electronegative $\mathrm{N}$ and $\mathrm{S}$ atoms. As part of the coordination sphere of $\mathrm{Fe}$, the two trans NCS groups generate a negative potential cavity at the center of the $\mathrm{FeN}_{6}$ octahedron. The $\mathrm{Fe}-\mathrm{NCS}$ interactions can be classified as mainly closed-shell, with nevertheless a significant covalent contribution, characterized by non-null populations of the iron $\mathrm{d}_{z}{ }^{2}$ atomic orbital resulting from $\sigma$ donation. On the other hand, the btr group is slightly positively charged and therefore contributes to regions of positive electrostatic potential. The ED and laplacian at the $\mathrm{Fe}-\mathrm{N} 11$ and $\mathrm{Fe}-\mathrm{N} 21$ BCPs are higher than those at the $\mathrm{Fe}-\mathrm{N}$ one; the corresponding coordination bonds exhibit a more pronounced covalent character.

On going from the LS to the HS state, the ED at all the $\mathrm{Fe}-\mathrm{N}$ BCPs decreases; the covalent contribution to the bonding interaction is reduced. Correlatively, the negative NCS and positive $\mathrm{Fe}$ charges are reinforced, confirming more ionic interactions. The central electronegative potential cavity is enlarged and elongated in the NCS direction. Owing to these bonding modifications, the amplitudes of thermal vibration of the NCS and btr moieties are systematically increased; the $\mathrm{Fe}-\mathrm{N}$ force constants are reduced in the HS state.
On the basis of these chemical bonding characteristics, we can try to explain the role played by the different fragments of the structure in the spin transition properties of $\mathrm{Fe}(\mathrm{btr})_{2}(\mathrm{NCS})_{2}$. $\mathrm{H}_{2} \mathrm{O}$ and generalize to other spin crossover materials. The NCS group generates the major contribution to the crystal field at the central metal site by having strong electrostatic interactions. The btr group acts as a potentially covalent $\sigma$ donor and $\pi$ acceptor, aiming at fine-tuning the crystal field to bring the crystal field splitting value $\Delta$ in the range of spin crossover. In the broad family of spin transition materials, it is understandable that most of these are constituted by two NCS groups and aromatic $\mathrm{N}$-containing ligands, the $\mathrm{N}$ atom allowing strong $\mathrm{Fe}-\mathrm{N}$ orbital overlaps. These arguments are well accepted in the chemistry community but have been experimentally evidenced for the first time in the present discussion.

Acknowledgment. The University Henri Poincaré, Nancy I, and the CNRS are gratefully acknowledged. V.L. is indebted to the Ministère de l'Education Nationale, de l'Enseignement Supérieur et de la Recherche for a doctoral fellowship. This work was partially supported by the European Union FP6Network of Excellence MAGMANet under contract no. FP6515767-2. N.L. thanks the "Mission Formation Permanente" of the DR14-CNRS. 